\title{
A Review of Bispectral Index Utility in Neurocritical Care Patients
}

\author{
Hossein Yousefi-Banaem ${ }^{1}$, Reza Goharani ${ }^{2}$, Mohammadreza Hajiesmaeili ${ }^{2}$, Arash Tafrishinejad ${ }^{2}$, \\ Masoud Zangi $^{2}$, Mahdi Amirdosara ${ }^{2}$ and Masoud Nashibi ${ }^{2,}$ \\ ${ }^{1}$ Skull Base Research Center, Loghman Hakim Hospital, Shahid Beheshti University of Medical Sciences, Tehran, Iran \\ ${ }^{2}$ Anesthesiology Research Center, Anesthesia and Critical Care Department, Shahid Beheshti University of Medical Sciences, Tehran, Iran \\ "Corresponding author: Anesthesiology Research Center, Anesthesia and Critical Care Department, Shahid Beheshti University of Medical Sciences, Tehran, Iran. Email: \\ masoudnashibi@yahoo.com
}

Received 2019 September 15; Revised 2020 May 16; Accepted 2020 May 28.

\begin{abstract}
Context: Bispectral Index (BIS) was introduced in 1960 to monitor the depth of anesthesia in the operating rooms. It has been recently used to monitor the sedation in the critically ill patients hospitalized in intensive care and neurocritical care units (NCCU). Evidence Acquisition: Patients in the NCCU, particularly those with prolonged mechanical ventilation require appropriate adjustments in the administration of sedative drugs. Similarly, those who require neuro protection with barbiturates need to be closely monitored in the depth of their coma.

Results: BIS may be a useful tool in this situation, and it can also help shorten the duration of mechanical ventilation by determining the appropriate time to eliminate patients from mechanical ventilation. We conducted a literature search to evaluate the utility of BIS monitoring in the NCCU patients with subarachnoid hemorrhage, intracranial hemorrhage, coma, cerebral hypoxia, status epilepticus and traumatic brain injury.

Conclusions: BIS monitoring may be a useful adjunct to take care of the patients. However, further studies with a larger population and better design are required to substantiate the role of BIS monitoring in the care of NCCU patients.
\end{abstract}

Keywords: Bispectral Index, Neurocritical Care, Monitoring

\section{Context}

Bispectral analysis was first introduced in 1960 to analyze the EEG waveforms and generate a numerical output which ranges from zero (EEG suppression) to 100 (full consciousness) by merging the attained data with a sophisticated algorithm. Figure 1 Aspect Medical Systems, Inc offered the first commercial BIS in 1993. US Food and Drug Administrative (FDA) approved the BIS monitoring in 1996, as a tool to evaluate and monitor the effect of anesthetics and sedative drugs. Previous studies have shown the BIS index values between 40 and 60 to indicate the appropriate level of general anesthesia (1-3).

Providing adequate and safe analgesia and sedation for patients in intensive care units, particularly for procedures and mechanical ventilation, is an essential component of ICU care. Frequent monitoring of the sedation depth can ensure the achievement and maintenance of the desired level of sedation (4-6).

Ramsay Sedation Scale (RSS), Sedation-Agitation Score (SAS) and Glasgow Coma Scale (GCS) are commonly clinical tools to monitor sedation, agitation, and level of consciousness, respectively in the ICU (7). RSS scales patients into six levels of sedation from restlessness to deep coma and SAS defines 7 levels of agitation and sedation from unarousable to dangerously agitated state. Other clinical/physiological signs such as heart rate, blood pressure, sweating, pupillary size, body movements, eye-opening and tears have also been employed to evaluate the state of sedation and analgesia $(8,9)$. However, these measures have several limitations and could be influenced by many other factors that may lead to over-sedation or undersedation. Therefore, the quantitative methods such as direct brain activity monitoring by the EEG signal analysis could be an effective adjunct to monitor the depth of sedation in the ICU (10-14).

\section{Application of BIS During General Anesthesia}

General anesthesia (GA) consists of three stages: induction, maintenance, and recovery. By applying the BIS monitoring, we can obtain useful information in the course of each stage of anesthesia. During the maintenance phase of GA, the optimum range of the BIS index is between 40 and 60. Maintaining the BIS index in this range reduces the 


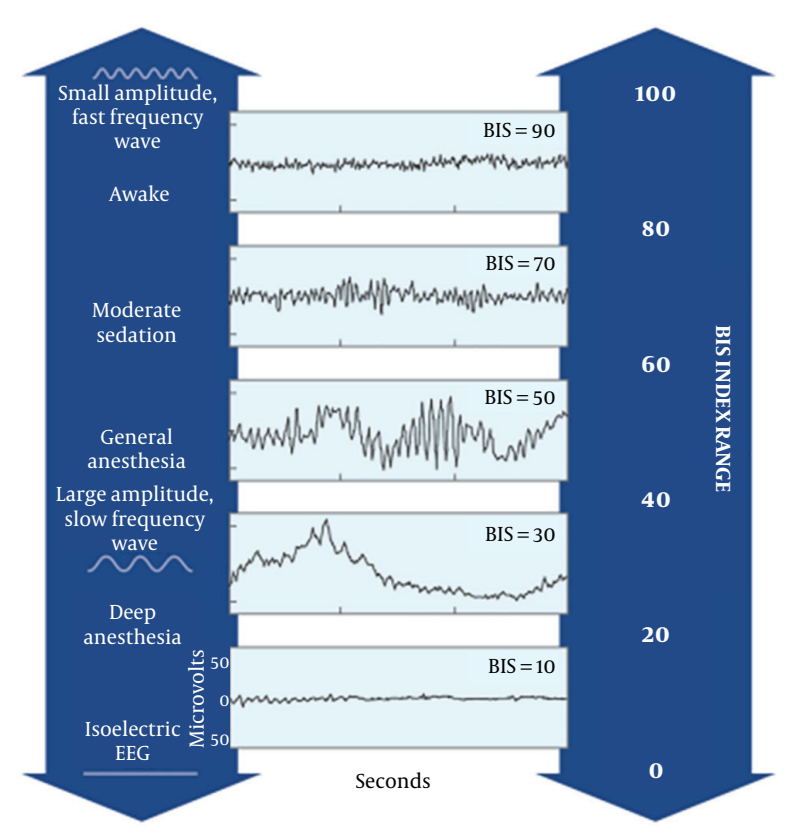

Figure 1. BIS index numerical values, zero (EEG suppression) to 100 (fully consciousness)

anesthetic drug usage and shortens the emergence time in the PACU.

If the anesthetic agents fail to create or maintain an adequate anesthesia depth, there is significant potential for the patient to regain sensorium during the maintenance phase of anesthesia. The operation recall is one of the most important reasons for grave emotional and physical consequences to the patient; it is one of the most important complaints against anesthesiologists. Therefore, anesthesiologists are determined to minimize the level of consciousness and maintain appropriate anesthesia depth while using the minimum required amounts of anesthetic agents.

A study based on the BIS monitoring with a large sample size $(n=967)$ showed that the incidence of recall was minimal (0.62\%) in GA during surgery. Several other studies have indicated BIS monitoring to reduce the anesthetic drugs and opiates use during general anesthesia $(15,16)$. In addition, the reduction in the incidence of awakening during anesthesia and the anesthesia recovery time were shown in multiple other studies $(17,18)$.

Cognitive impairment and delirium are other potential side effects of GA. Studies have indicated a reduction of these complications via BIS during GA (19). Furthermore, Herrero et al. showed BIS monitoring potentials in the early detection of neurological complications in the PACU and consequently improved survival with their prompt management (20).
Despite the BIS monitoring and inappropriately higher doses of the anesthetic drugs administration, wakefulness during surgery has also been reported in the literature. Morse et al. used BIS to monitor sedation levels in patients undergoing oral surgery with anesthesia by midazolam and a midazolam-ketamine combination. They showed that ketamine does not affect the BIS value which remained close to the baseline. They concluded that BIS monitoring was not useful in their study subjects (21). The use of BIS in general anesthesia is listed in Table 1.

\begin{tabular}{|c|c|c|c|}
\hline & Variables & Effects of BIS on Variable & References \\
\hline $\mathbf{1}$ & Sedative dosage & $\begin{array}{l}\text { Reduce the sedative } \\
\text { dosage }\end{array}$ & $(15,16)$ \\
\hline 2 & Awareness & $\begin{array}{l}\text { reduce the incidence of } \\
\text { unexpected awareness } \\
\text { during surgery }\end{array}$ & $(17,22-25)$ \\
\hline 3 & Recovery time & $\begin{array}{l}\text { BIS monitoring in } \\
\text { craniotomy reduced the } \\
\text { anesthetic and narcotic } \\
\text { drug dosage and lowered } \\
\text { the recovery times }\end{array}$ & $(17,18)$ \\
\hline 4 & $\begin{array}{l}\text { Postoperative delirium } \\
\text { and cognition }\end{array}$ & $\begin{array}{l}\text { BIS-guided anesthesia } \\
\text { reduced anesthetic } \\
\text { dosage and decreased the } \\
\text { risk of postoperative } \\
\text { cognitive dysfunction at } 3 \\
\text { months after surgery }\end{array}$ & (19) \\
\hline 5 & $\begin{array}{l}\text { Postoperative } \\
\text { surveillance }\end{array}$ & $\begin{array}{l}\text { BIS with the assessment } \\
\text { of pupils, GCS, CNS, } \\
\text { Nu-DESC improved early } \\
\text { detection of } \\
\text { postoperative } \\
\text { neurological } \\
\text { complications in the } \\
\text { Post-Anesthesia Care Unit } \\
\text { (PACU) after elective } \\
\text { craniotomies. }\end{array}$ & $(20)$ \\
\hline 6 & Muscle relaxant & Not studied & - \\
\hline
\end{tabular}

\section{Application of BIS in the ICU}

Inadequate sedation in the ICU may lead to significant patient discomfort and pain while over-sedation increases the risk of ventilator-related events and longer ICU stay. However, the BIS monitoring application in the ICU differs from the operating room, considerably by broader BIS index range and diversity of clinical scenarios observed in the $\operatorname{ICU}(26,27)$.

BIS monitoring could be beneficial for the ICU patients, both clinically and financially. Some studies have shown that administration of adequate sedation and analgesia, guided by BIS index, have significantly decreased both the ICU painful events, medication and overall ICU cost $(28,29)$. However, other studies in patients receiving sedation in 
the ICU have shown the BIS index to correlate poorly with the Sedation-Agitation Scale $(12,14,30)$.

Unlike the monitoring of consciousness and pain perception by the vital signs, BIS is more sensitive in patients undergoing invasive procedures in the ICU, such as intubation, tracheostomy, chest tube placement bronchoscopy, etc $(31,32)$. However, BIS readings could be rendered less reliable in clinical situations, such as administration of relatively low-level sedation, minor interventions, administration of neuromuscular blockade (NMB), electrical noise interference and abnormal brain function (33). False elevation and false reduction of the BIS index values could be seen in the accentuated EMG signals and administration of NMBs, respectively.

Due to the complexity of care in the ICU and the variety of conditions that may interfere with reliable BIS readings, the determination of optimal sedation based on this modality alone could result in inappropriate administration of sedative drugs which may result in over-or-undersedation. In general, higher BIS indices may be more applicable for the ICU patients than the values used in the general anesthesia in the operating room (34).

Gill et al. tried to validate the BIS values in the intubated ICU patients. Sedation was monitored by recording the clinical parameters and the BIS values. They observed that BIS could not predict reliable values for appropriate sedation in the intubated patients (35). Olson et al. studied potential benefits of BIS in the ICU, illustrating that there was a relationship between the comatose state and BIS value (36). Other studies showed a better correlation between the level of sedation and BIS values in the surgical ICU patients than the heterogeneous patient groups in the general ICUs.

On the other hand, Bell et al. found significant correlations between the BIS values and the Ramsay Sedation Scale. They showed the BIS values of 87.2 and 80.9 corresponded to an RSS of 3 and 4, respectively (37-39). Adesanya et al. conducted a study to compare BIS values with the patient state index. The patient state index (PSI) is a clinicallyvalidated measure of the effect of anesthesia and sedation. The PSI is calculated by a high-resolution 4-channel electroencephalograph (EEG) after advanced noise reduction. Results showed a significant correlation in the oversedation but not under-sedation situations compared with these two modalities (40).

Dou et al. examined the utility of the BIS index for monitoring patients in a coma. They demonstrated that BIS values could correlate well with the prognosis of coma in the ICU (41). Subsequently, other investigators showed the BIS indices to correlate well with the prognosis of patients in coma and to assist with brain death determination in the comatose patients (41-44).
Some applications of BIS in the ICU are summarized in Table 2.

Table 2. Application of BIS in the ICU. (Sedation Type, Sedation Dose, Sedation Score and Side Effects)

\begin{tabular}{|c|c|c|}
\hline Variable & $\begin{array}{l}\text { Effect of BIS on } \\
\text { Variable }\end{array}$ & References \\
\hline Medication dosage & & $(15,16,21,32,34,45-49)$ \\
\hline Propofol & $\begin{array}{l}\text { Reduction of dosage to } \\
\text { obtain desire sedation } \\
21 \%\end{array}$ & \\
\hline Midazolam & $\begin{array}{l}\text { Reduction of dosage to } \\
\text { obtain desire sedation }\end{array}$ & \\
\hline $\begin{array}{l}\text { Dexmedetomi- } \\
\text { dine }\end{array}$ & Reduce sedative dosage & \\
\hline Sedation scores & & $(31,39,40,50)$ \\
\hline RSS & $\begin{array}{l}\text { BIS correlated with } \\
\text { Ramsay }\end{array}$ & \\
\hline PSI & BIS correlated with PSI & \\
\hline GCS & BIS correlated with GCS & \\
\hline Adverse effect & & $(12,25,31,40,51)$ \\
\hline Over sedation & $\begin{array}{l}\text { Prevent from over } \\
\text { sedation }\end{array}$ & \\
\hline Under sedation & $\begin{array}{l}\text { Prevent from under } \\
\text { sedation }\end{array}$ & \\
\hline Awareness & $\begin{array}{l}\text { Prevent from unwanted } \\
\text { awareness }\end{array}$ & \\
\hline $\begin{array}{l}\text { Depressed } \\
\text { cardiac } \\
\text { contractility }\end{array}$ & Decrease & \\
\hline Hypotension & Decrease & \\
\hline
\end{tabular}

Abbreviations: GCS, Glasgow Coma Scale; PSI, Patient State Index; RSS, Ramsey Sedation Scale

\section{Application of BIS in the NCCU}

Traumatic brain injury (TBI), subarachnoid hemorrhage (SAH), refractory intracranial hypertension (RICH), cerebral vasospasm, different types of strokes, coma, cerebral hypo-perfusion and ischemic-hypoxic brain injuries and seizures are the main pathologies in the neurocritical care ICUs $(51,52)$.

Studies on patients with TBI have shown a significant correlation between BIS values and the levels of consciousness. BIS was found to be useful in monitoring the sedation level and the early detection of brain death in TBI patients (38, 43, 51, 53-55). Moghaddam et al. monitored BIS for several days in patients with different brain injuries, such as cerebral contusion, subdural hemorrhage, and SAH. In their study the BIS values were not significantly different after two days of monitoring in different pathologies, they were significantly different in different brain lesions after three days (55). 
Some case reports have shown that the BIS indices have high sensitivity and specificity in monitoring the depth of sedation in the SAH patients (56-58). The use of BIS index and other interventions such as intracranial pressure monitoring, long-term mild hypothermia, and oncotic therapy, could assist the management of RICH (59). A study on 89 patients with SAH monitored by the BIS and GCS values showed statistically significant correlations between these two modalities and the level of alertness, BIS $(\mathrm{r}=0.723, \mathrm{P}<$ $0.01)$ and GCS $(r=0.646, P<0.01)$. The BIS index increased with an increasing level of alertness. The mean BIS values measured for coma, semi-coma, stupor and drowsiness were; $0.14 \pm 0.23,38.9 \pm 18.0,60.3 \pm 14.5$, and $73.6 \pm 16.5$, respectively $(42,43)$. In another study, BIS values did not correlate well with the SAH induced cerebral vasospasm (42).

The study of BIS values and the ischemic-hypoxic brain injury has had conflicting results. Some have shown the positive correlation of the BIS values to the extent of ischemic-hypoxic brain injury, especially in the frontal region, and demonstrated a sudden drop in these values to be associated with cerebral hypo-perfusion (60-65). Some studies did not support these observations (66).

BIS has also been studied in seizure disorders, and significant alterations have been reported in its values during seizure (67). Based on the frequencies of the ictal waveform, the BIS values can decrease or increase. BIS may be useful in monitoring seizures in patients on NMB where clinical detection of seizures could be difficult (67).

BIS values may be altered by the EMG signal variations, induced by the facial nerve stimulation in a seizure. Thus, such variations in the BIS values may portend seizure activity and prompt the need for immediate intervention (10).

Musialowicz et al. monitored the patients with refractory status epilepticus (RSE) in neurocritical care units by BIS and continuous EEG monitoring. They found that the BIS value of 30 could detect burst suppression and have sensitivity and specificity of $99 \%$ and $98 \%$ respectively. However, the BIS indices could not recognize the regional epileptic activity (49). Table 3 shows the use of BIS in NCCU as follows:

\section{Conclusions}

Interpreting the EEG signals could be a challenging task for critical care physicians. Providing numerical values driven from the EEG signals, the BIS index is a relatively easy tool for evaluating the conscious state of patients during anesthesia and recovery. Its application has been studied in other critical care settings, such as monitoring the depth of sedation in the ICU and many other situations in the NCCUs. However, this modality still requires more rigorous investigations before it could find its place in NCCU.

\begin{tabular}{|c|c|c|}
\hline Variable & Effect of BIS on Variable & References \\
\hline \multicolumn{3}{|l|}{$\begin{array}{l}\text { Neuro-surgical critical } \\
\text { care }\end{array}$} \\
\hline 1. TBI & $\begin{array}{l}\text { Significantly correlated } \\
\text { with the level of } \\
\text { consciousness. BIS can } \\
\text { track levels of sedation in } \\
\text { traumatic brain injury } \\
\text { patients. Early detection of } \\
\text { brain death in patients } \\
\text { with severe acute TBI. }\end{array}$ & $(38,43,51,53-55)$ \\
\hline 2. SAH & $\begin{array}{l}\text { BIS showed high } \\
\text { sensitivity and specificity } \\
\text { in sedated patients after } \\
\text { subarachnoid } \\
\text { hemorrhage. }\end{array}$ & $(56-58)$ \\
\hline 3. $\mathrm{RICH}$ & $\begin{array}{l}\text { BIS combined with } \\
\text { intracranial pressure } \\
\text { monitoring, long term } \\
\text { mild hypothermia, } \\
\text { hypertonic therapy helped } \\
\text { to control refractory ICH. }\end{array}$ & (59) \\
\hline $\begin{array}{l}\text { 4. Cerebral } \\
\text { vasospasm }\end{array}$ & Was not detectable by BIS. & $(42)$ \\
\hline \multicolumn{3}{|l|}{$\begin{array}{l}\text { Neurological critical } \\
\text { care }\end{array}$} \\
\hline 1. Coma & $\begin{array}{l}\text { BIS is correlated with the } \\
\text { prognosis of patients with } \\
\text { coma in the ICU. BIS can be } \\
\text { used in severely comatose } \\
\text { patients as an assessment } \\
\text { of brain death. }\end{array}$ & $(41-44)$ \\
\hline \multirow[t]{2}{*}{$\begin{array}{l}\text { 2. Cerebral } \\
\text { hypo-perfusion } \\
\text { and } \\
\text { ischemic-hypoxic } \\
\text { brain injury }\end{array}$} & $\begin{array}{l}\text { Correlated with frontal } \\
\text { region hypo-perfusion. } \\
\text { Sudden deterioration in } \\
\text { BIS values probably } \\
\text { indicate cerebral } \\
\text { hypo-perfusion. }\end{array}$ & $(60-64)$ \\
\hline & $\begin{array}{l}\text { Some studies, however, } \\
\text { have not found a } \\
\text { significant correlation } \\
\text { between BIS values and } \\
\text { cerebral hypo-perfusion. }\end{array}$ & (66) \\
\hline 3. RSE & $\begin{array}{l}\text { Increased BIS values with } \\
\text { the onset of seizure. }\end{array}$ & $(68-70)$ \\
\hline
\end{tabular}

Abbreviations: RICH, refractory intracranial hypertension; RSE, refractory statues epilepticus; $\mathrm{SAH}$, subarachnoid hemorrhage; TBI, traumatic brain injury

\section{Acknowledgments}

The authors would like to thank the Clinical Research Development Unit (CRDU) of Loghman Hakim Hospital, Shahid Beheshti University of Medical Sciences, Tehran, Iran for their support, cooperation, and assistance throughout the study.

\section{Footnotes}

Authors' Contribution: Study concept and design: Hossein Yousefi-Banaem and Mohamadreza Hajiesmaeili. 
Drafting of the manuscript: Yousefi-Banaem. Critical revision of the manuscript for important intellectual content: Goharani, Nashibi, Tafrishinejad, Zangi, and Amirdosara.

Conflict of Interests: The authors certify that they have no affiliations with or involvement in any organization or entity with any financial interest (such as honoraria; educational grants; participation in speakers' bureaus; membership, employment, consultancies, stock ownership, or other equity interest; and expert testimony or patentlicensing arrangements), or non-financial interest (such as personal or professional relationships, affiliations, knowledge or beliefs) in the subject matter or materials discussed in this manuscript.

\section{Ethical Approval: IR.SBMU.RETECH.REC.1397.433.}

Funding/Support: Authors certify that no funding has been received for the conduct of this study and/or preparation of this manuscript.

\section{References}

1. Kelley S. Monitoring consciousness Using the Bispectral IndexTM during anesthesia. COVIDIEN; 2007.

2. Strum DP, Sampson AR, May JH, Vargas LG. Surgeon and type of anesthesia predict variability in surgical procedure times. Anesthesiology: The Journal of the American Society of Anesthesiologists. 2000;92(5):145466.

3. Talke PO, Sharma D, Heyer EJ, Bergese SD, Blackham KA, Stevens RD. Republished: Society for Neuroscience in Anesthesiology and Critical Care expert consensus statement: Anesthetic management of endovascular treatment for acute ischemic stroke. Stroke. 2014;45(8):e138-50.

4. Brown EN, Lydic R, Schiff ND. General anesthesia, sleep, and coma. New England Journal of Medicine. 2010;363(27):2638-50.

5. Kil HY, Lee SI, Lee SJ, Lee SW, Lee DH. The bispectral index and modified observer's assessment of alertness/sedation scale comparable to effect site concentration of propofol in Koreans. Korean Journal of Anesthesiology. 2000;38(2):251-7.

6. Reschreiter H, Kapila A. Ramsey sedation score. Surgery. 2006;10(24):342-5.

7. Arbabi M, Zebardast J, Noorbala AA, Mohamadi M, Rahimnia M, Larijani R. Efficacy of Liaison Education and Environmental Changes on Delirium Incidence in ICU. archive of neroscience. 2018;5(2).

8. Dabbagh A, Rajaei S. Sleep and anesthesia: can we use a physiologic model to decrease risks of a medical intervention. Journal of Cellular \& Molecular Anesthesia. 2017;2(2):77-81.

9. Dabbagh A, Rajaei S, Golzari SE. History of anesthesia and pain in old Iranian texts. Anesthesiology and pain medicine. 2014;4(3).

10. Clavero FI, Medel GT, de Orte Sancho K, Uriarte AG, Martínez AI, Ruíz AM. Use of BIS VISTA ${ }^{\mathrm{TM}}$ bilateral monitor for diagnosis of intraoperative seizures, a case report. Revista espanola de anestesiologia y reanimacion. 2015;62(10):590-5.

11. Faritous Z, Barzanji A, Azarfarin R, Ghadrdoost B, Ziyaeifard M, Aghdaei $\mathrm{N}$, et al. Comparison of Bispectral Index Monitoring With the Critical-Care Pain Observation Tool in the Pain Assessment of Intubated Adult Patients After Cardiac Surgery. Anesthesiology and Pain Medicine. 2016;6(4).

12. Hajat Z, Ahmad N, Andrzejowski J. The role and limitations of EEGbased depth of anaesthesia monitoring in theatres and intensive care. Anaesthesia. 2017;72(S1):38-47.
13. Miller CM, Torbey MT. Neurocritical care monitoring. Demos Medical Publishing; 2014

14. Prottengeier J, Moritz A, Heinrich S, Gall C, Schmidt J. Sedation assessment in a mobile intensive care unit: a prospective pilot-study on the relation of clinical sedation scales and the bispectral index. Critical Care. 2014;18(6):615.

15. Jeleazcov C, Schmidt J, Ammon C, Schwilden H, Schüttler J, Fechner J. Pharmacodynamic modelling of the bispectral index response to propofol-based anaesthesia during general surgery in children. British Journal of Anaesthesia. 2008;100(4):509-516.

16. Quesada N, Júdez D, Ubieto JM, Pascual A, Chacón E, De Pablo F, et al. Bispectral index monitoring reduces the dosage of propofol and adverse events in sedation for endobronchial ultrasound. Respiration. 2016;92(3):166-75.

17. Oliveira CRD, Bernardo WM, Nunes VM. Benefit of general anesthesia monitored by bispectral index compared with monitoring guided only by clinical parameters. Systematic review and meta-analysis. Revista brasileira de anestesiologia. 2017;67(1):72-84.

18. Wong J, Song D, Blanshard H, Grady D, Chung F. Titration of isoflurane using BIS index improves early recovery of elderly patients undergoing orthopedic surgeries. Canadian Journal of Anesthesia. 2002;49(1):13-8.

19. Chan MT, Cheng BC, Lee TM, Gin T. BIS-guided anesthesia decreases postoperative delirium and cognitive decline. Journal of neurosurgical anesthesiology. 2013;25(1):33-42.

20. Herrero S, Carrero E, Valero R, Rios J, Fábregas N. Postoperative surveillance in neurosurgical patients-usefulness of neurological assessment scores and bispectral index. Revista brasileira de anestesiologia. 2017;67(2):153-65.

21. Morse Z, Kaizu M, Sano K, Kanri T. BIS monitoring during midazolam and midazolam-ketamine conscious intravenous sedation for oral surgery. Oral Surgery, Oral Medicine, Oral Pathology, Oral Radiology and Endodontics. 2002;94(4):420-4.

22. Sebel PS, Bowdle TA, Ghoneim MM, Rampil IJ, Padilla RE, Gan TJ, et al. The incidence of awareness during anesthesia: a multicenter United States study. Anesthesia \& Analgesia. 2004;99(3):833-9.

23. Gelfand ME, Gabriel RA, Gimlich R, Beutler SS, Urman RD. Practice patterns in the intraoperative use of bispectral index monitoring. Journal of Clinical Monitoring and Computing. 2017;31(2):281-9. doi: 10.1007/s10877-016-9845-5.

24. O'Connor MF, Daves SM, Tung A, Cook RI, Thisted R, Apfelbaum J. BIS Monitoring to Prevent Awareness during General Anesthesia. Anesthesiology. 2001;93(3):520-522.

25. Ekman A, Lindholm ML, Lennmarken C, Sandin R. Reduction in the incidence of awareness using BIS monitoring. Acta Anaesthesiologica Scandinavica. 2004;48(1):20-6.

26. Kress JP, Pohlman AS, O'Connor MF, Hall JB. Daily interruption of sedative infusions in critically ill patients undergoing mechanical ventilation. New England Journal of Medicine. 2000;342(20):1471-7.

27. Sadhasivam S, Ganesh A, Robison A, Kaye R, Watcha MF. Validation of the bispectral index monitor for measuring the depth of sedation in children. Anesthesia \& Analgesia. 2006;102(2):383-8.

28. Bould MD, Mahtani DG, Davies R, Roughton M, Hunter DN, Kelleher A. Bispectral index values during elective rigid bronchoscopy: a prospective observational pilot study. Anaesthesia.2007;62(5):438-45.

29. Kaplan LJ, Bailey H. Bispectral index (BIS) monitoring of ICU patients on continuous infusion of sedatives and paralytics reduces sedative drug utilization and cost. Critical Care. BioMed Central; 2000. P190 p.

30. Hampshire P, McCrossan L. How is sedation provided for percutaneous dilatational tracheostomy in English ICUs? Critical Care. 2011;15(1):P349.

31. Consales G, Chelazzi C, Rinaldi S, De AG. Bispectral Index compared to Ramsay score for sedation monitoring in intensive care units. Minerva anestesiologica. 2006;72(5):329-36.

32. Triltsch AE, Welte M, Von Homeyer P, Groe J, Genähr A, Moshirzadeh $\mathrm{M}$, et al. Bispectral index-guided sedation with dexmedetomidine in 
intensive care: a prospective, randomized, double blind, placebocontrolled phase II study. Critical care medicine. 2002;30(5):1007-14.

33. Avidan MS, Palanca BJ, Glick D, Jacobsohn E, Villafranca A, O'Connor M, et al. Protocol for the BAG-RECALL clinical trial: a prospective, multicenter, randomized, controlled trial to determine whether a bispectral index-guided protocol is superior to an anesthesia gas-guided protocol in reducing intraoperative awareness with explicit recall in high risk surgical patients. BMC anesthesiology. 2009;9(1):8.

34. Greif R, Greenwald S, Schweitzer E, Laciny S, Rajek A, Caldwell JE, et al Muscle relaxation does not alter hypnotic level during propofol anesthesia. Anesthesia \& Analgesia. 2002;94(3):604-8.

35. Gill M, Green SM, Krauss B. A study of the bispectral index monitor during procedural sedation and analgesia in the emergency department. Annals of emergency medicine. 2003;41(2):234-41.

36. Olson DM, Chioffi SM, Macy GE, Meek LG, Cook HA. Potential Benefits of Bispectral Index Monitoring in Critical Care A Case Study. Critical Care Nurse. 2003;23(4):45-52.

37. Arbour R, Waterhouse J, Seckel MA, Bucher L. Correlation between the Sedation-Agitation Scale and the Bispectral Index in ventilated patients in the intensive care unit. Heart $\&$ Lung: The Journal of Acute and Critical Care. 2009;38(4):336-45.

38. Deogaonkar A, Gupta R, DeGeorgia M, Sabharwal V, Gopakumaran $\mathrm{B}$, Schubert A, et al. Bispectral Index monitoring correlates with sedation scales in brain-injured patients. Critical care medicine. 2004;32(12):2403-6.

39. Hernández-Gancedo C, Pestaña D, Peña N, Royo C, Pérez-Chrzanowska $\mathrm{H}$, Criado A. Monitoring sedation in critically ill patients: bispectral index, Ramsay and observer scales. European journal of anaesthesiology. 2006;23(8):649-53.

40. Adesanya AO, Rosero E, Wyrick C, Wall MH, Joshi GP. Assessing the predictive value of the bispectral index vs patient state index on clinical assessment of sedation in postoperative cardiac surgery patients. Journal of critical care. 2009;24(3):322-8.

41. Dou L, Gao HM, Lu L, Chang WX. Bispectral index in predicting the prognosis of patients with coma in intensive care unit. World journal of emergency medicine. 2014;5(1):53.

42. Brallier JW, Deiner SG. Use of the bilateral BIS monitor as an indicator of cerebral vasospasm in ICU patients. Middle East J Anaesthesiol. 2013;22:161.

43. Jung JY, Cho CB, Min BM. Bispectral index monitoring correlates with the level of consciousness in brain injured patients. Korean journal of anesthesiology. 2013;64(3):246-50.

44. Mahmood S. Bispectral index as a predictor of unsalvageable traumatic brain injury. J Critical Care. 2015;19(1):P450.

45. Hutt A, Longtin A. Effects of the anesthetic agent propofol on neural populations. Cognitive neurodynamics. 2010;4(1):37-59.

46. Anderson RE, Barr G, Jakobsson JG. Cerebral state index during anaesthetic induction: a comparative study with propofol or nitrous oxide. Acta anaesthesiologica scandinavica. 2005;49(6):750-3.

47. Kreuer S, Biedler A, Larsen R, Schoth S, Altmann S, Wilhelm W. The Narcotrend ${ }^{\mathrm{TM}}$-a new EEG monitor designed to measure the depth of anaesthesia A comparison with bispectral index monitoring during propofol-remifentanil-anaesthesia. Der Anaesthesist. 2001;50(12):9215.

48. Anderson RE, Jakobsson JG. Entropy of EEG during anaesthetic induction: a comparative study with propofol or nitrous oxide as sole agent. British Journal of Anaesthesia. 2004;92(2):167-70.

49. Musialowicz T, Mervaala E, Kälviäinen R, Uusaro A, Ruokonen E, Parviainen I. Can BIS monitoring be used to assess the depth of propofol anesthesia in the treatment of refractory status epilepticus? Epilepsia. 2010;51(8):1580-6.

50. Liu H, Liu Y, Xu Y, Xue Y. Prognostic evaluation of bispectral index in patients following cardiopulmonary resuscitation. Experimental and therapeutic medicine. 2013;5(3):907-11.
51. Fernández-Espejo D, Owen AM. Detecting awareness after severe brain injury. Nature Reviews Neuroscience. 2013;14(11):801.

52. Pandit JJ, Schmelzle-Lubiecki B, Goodwin M, Saeed N. Bispectral indexguided management of anaesthesia in permanent vegetative state. Anaesthesia. 2002;57(12):1190-4.

53. Badenes R, García-Pérez ML, Maruenda A, Aguilar G, Belda FJ. Bispectral index monitoring in traumatic brain injury patients: 7AP4-6. European Journal of Anaesthesiology. 2007;24:80.

54. Mahmood S, El-Menyar A, Shabana A, Mahmood I, Asim M, Abdelrahman $\mathrm{H}$, et al. Bispectral index as a predictor of unsalvageable traumatic brain injury. Brain injury. 2017;31(10):1382-6.

55. Moghaddam OM, Lahiji MN, Hassani V, Gezik FK, Farazi E. Relationship between type of brain injury with Bispectral Index monitoring in intubated ICU trauma patients. Tehran University Medical Journal. 2015;73(2).

56. Duncan D, Kelly KP, Andrews PJD. A comparison of bispectral index and entropy monitoring, in patients undergoing embolization of cerebral artery aneurysms after subarachnoid haemorrhage. British Journal of Anaesthesia. 2006;96(5):590-6.

57. Wang AY, Huang $\mathrm{CH}$, Chang WT, Chen WJ. Bispectral index monitoring in subarachnoid hemorrhage-associated out-of hospital cardiac arrest. The American journal of emergency medicine. 2016;34(5):934. e1-3.

58. Yatabe T, Yokoyama T, Yokoyama R, Tokoroyama H, Yamashita K, Manabe $M$. A case of subarachnoid hemorrhage with different BIS values observed between the right and left forehead. Masui. The Japanese journal of anesthesiology. 2007;56(11):1362-4.

59. Cao C, Gao H, Wu W, Wang HX, Yang L. A Combined Strategy of Sedation Guided by Bispectral Index, ICP Monitoring and Mild Hypothermia to Deal with Refractory Intracranial Hypertension: A Case Report. Brain Disord Ther. 2018;7(242):2.

60. Flores A, Ribó M, Rubiera M, Gonzalez-Cuevas M, Pagola J, RodriguezLuna D, et al. Monitoring of cortical activity postreperfusion. A powerful tool for predicting clinical response immediately after recanalization. Journal of Neuroimaging. 2015;25(2):257-62.

61. Kumar TB, Puri GD. Bispectral index as a possible early marker of cerebral hypoperfusion. Anesthesia, essays and researches. 2013;7(3):405.

62. Myles PS. Bispectral Index Monitoring in Ischemic-Hypoxic Brain Injury. The journal of extra-corporeal technology. 2009;41(1):P15.

63. Hayashida M, Chinzei M, Komatsu K, Yamamoto H, Tamai H, Orii $\mathrm{R}$, et al. Detection of cerebral hypoperfusion with bispectral index during paediatric cardiac surgery. British journal of anaesthesia. 2003;90(5):694-8.

64. Hemmerling TM, Olivier J, Basile F, Le N, Prieto I. Bispectral index as an indicator of cerebral hypoperfusion during off-pump coronary artery bypass grafting. Anesthesia. 2005;100(2):354-6.

65. Shirvani M, Delam H, Karimizade M. Brain Infection After Cesarean Section: A Case of Subdural Empyema Post-Cesarean Section. Archives of Neuroscience. 2018;5(4).

66. Deogaonkar A, Vivar R, Bullock RE, Price K, Chambers I, Mendelow AD. Bispectral index monitoring may not reliably indicate cerebral ischaemia during awake carotid endarterectomy. British journal of anaesthesia. 2005;94(6):800-4.

67. Dahaba AA, Liu DW, Metzler H. Bispectral index (BIS) monitoring of acute encephalitis with refractory, repetitive partial seizures (AERRPS). Minerva anestesiologica. 2010;76(4):298-301.

68. Fernandez-Torre JL, Hernandez-Hernandez MA. Utility of bilateral Bispectral index (BIS) monitoring in a comatose patient with focal nonconvulsive status epilepticus. Seizure. 2012;21(1):61-4.

69. Tallach RE, Ball DR, Jefferson P. Monitoring seizures with the Bispectral index. Anaesthesia. 2004;59(10):1033-4.

70. Haesen J; Desteghe L; Meex I; Genbrugge C; Demeestere J; Ernon L, et al. Use of bispectral index EEG monitoring for a fast and reliable detection of epileptic activity in postcardiac arrest patients. Critical Care. 2015;19(1). doi: 10.1186/cc14514. 